near water bodies with cyanobacteria blooms was a risk factor for ALS. ${ }^{3}$

It is likely that sporadic ALS is a multifactorial disease, resulting from the interaction of multiple environmental risk factors with multiple genetic predisposing factors. Therefore, studies of regional distribution of cases and of underlying genetic factors may fail if they do not focus on individual risk factors.

Author Response: James P. Rooney, Anthony Staines, Orla Hardiman, Dublin: We thank Bradley et al. for their interest and comments on our article. ${ }^{1}$ We agree that "If cases are aggregated over large areas, the effect of a localized toxic exposure may be lost." Therefore, we have undertaken a new study where we replicated our analysis at a higher spatial resolution of over 18,000 small areas consisting of no more than 200 residences each. $^{6}$

We also agree that "sporadic ALS is a multifactorial disease, resulting from the interaction of multiple environmental risk factors with multiple genetic predisposing factors." There is recent epidemiologic evidence for this in the form of multistep models for ALS. ${ }^{7}$ We are also cognizant of the ecological fallacy (i.e., inappropriately ascribing group-level correlations to individual-level variables), and agree that individual risk factors are important to include in models wherever possible.
However, our study did report positive results. Our methods were sensitive enough to find 2 statistically significant low-risk areas, as well as detect 5 cases that presented late and 2 that presented cross-border. The algorithms used are agnostic to hot or cold spots; therefore, if hot spots did exist, we are confident we would have detected them.

C) 2015 American Academy of Neurology

1. Rooney J, Vajda A, Heverin M, et al. Spatial cluster analysis of population amyotrophic lateral sclerosis risk in Ireland. Neurology 2015;84:1537-1544.

2. Caller TA, Chipman JW, Field NC, Stommel EW. Spatial analysis of amyotrophic lateral sclerosis in Northern New England, USA, 1997-2009. Muscle Nerve 2013;48:235-241.

3. Torbick N, Hession S, Stommel E, Caller T. Mapping amyotrophic lateral sclerosis lake risk factors across northern New England. Int J Health Geogr 2014;13:1.

4. Sabel CE, Boyle PJ, Löytönen M, et al. Spatial clustering of amyotrophic lateral sclerosis in Finland at place of birth and place of death. Am J Epidemiol 2003;157:898-905.

5. Wheeler DC. A comparison of spatial clustering and cluster detection techniques for childhood leukemia incidence in Ohio, 1996-2003. Int J Health Geogr 2007;6:13.

6. Rooney JP, Tobin K, Crampsie A, et al. Social deprivation and population density are not associated with small area risk of amyotrophic lateral sclerosis. Environ Res 2015;142: 141-147.

7. Al-Chalabi A, Calvo A, Chio A, et al. Analysis of amyotrophic lateral sclerosis as a multistep process: a population-based modelling study. Lancet Neurol 2014;13:1108-1113.

\title{
CORRECTION
}

\section{CNS neutrophilic vasculitis in neuro-Sweet disease}

In the Clinical/Scientific Note "CNS neutrophilic vasculitis in neuro-Sweet disease" by R. Charlson et al. (Neurology ${ }^{\circledR}$ 2015;85:829-830), there is an error in the discussion and the references. The last name of the first author of reference 2 should be Hisanaga, not Hisanga as originally published. The authors regret the error. 


\section{Neurology}

\section{CNS neutrophilic vasculitis in neuro-Sweet disease \\ Neurology 2015;85;1823 \\ DOI 10.1212/WNL.0000000000002139}

This information is current as of November 16, 2015

\section{Updated Information \&}

Services

Permissions \& Licensing

Reprints including high resolution figures, can be found at: http://n.neurology.org/content/85/20/1823.full

Information about reproducing this article in parts (figures,tables) or in its entirety can be found online at:

http://www.neurology.org/about/about_the_journal\#permissions

Information about ordering reprints can be found online:

http://n.neurology.org/subscribers/advertise

Neurology $®$ is the official journal of the American Academy of Neurology. Published continuously since 1951, it is now a weekly with 48 issues per year. Copyright (C 2015 American Academy of Neurology. All rights reserved. Print ISSN: 0028-3878. Online ISSN: 1526-632X.

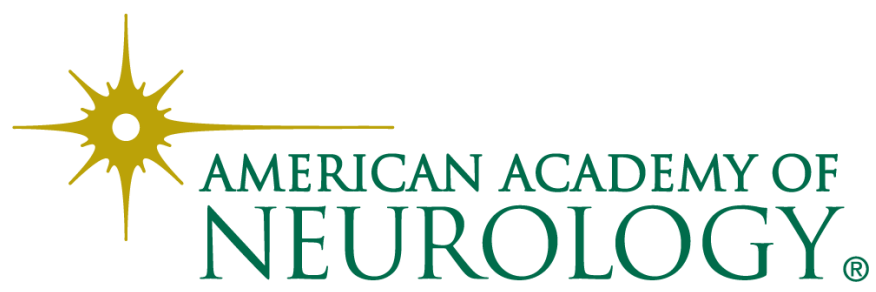

